\title{
Study on Safety Investment Performance of Stakeholders in Wind Farms Based on Evaluation Game Model
}

\author{
Rui Liu and Taihua Yang* \\ School of Economics \& Management, Shanghai University of Electric Power, Shanghai, China, 200090
}

\begin{abstract}
This paper starts from the main stakeholders of safety input performance, from the government regulatory departments and wind power enterprises, grid companies, the three relevant stakeholders to conduct safety investment performance game analysis, establish a game income function and strategy analysis model, explain their mutual Game strategy relationship. Studies have shown that strengthening the government's electric supervision department's safety supervision and related policy support is an important means to promote wind power enterprises to take the initiative to carry out safety investment. Power grid enterprises actively choose green wind power, which can promote the development and utilization of green energy.
\end{abstract}

Keywords—safety input performance; evolutionary game model

\section{INTRODUCTION}

Under the environment of strengthening energy conservation and emission reduction in the world, China's wind power generation has developed rapidly and has become one of the important sources of power supply in China. The safety performance of wind farm projects refers to the measurable results obtained by the power production stakeholders in terms of safety management according to the power safety production targets, and reflects the control effect of the organization occupational health and safety management system on safety risks. A well-functioning and functioning occupational health and safety management system and risk control require adequate safety inputs. Obviously, safety performance is closely related to safety investment and safety cost control in safety management. Different safety behaviors have different selection strategies in terms of safety investment and safety cost control, resulting in different safety performance.

Jimmie Hinze et al. ${ }^{[1]}$ studied the relationship between safety strategy and safety performance in the construction industry project. Based on the analysis of a large number of sample safety measures, 22 basic safety indicators and 14 key strategic measures to improve safety performance were identified. Jingdong Yan et al. ${ }^{[2]}$ conducted research on China's electric power safety supervision and early warning system, and established 18 secondary indicators such as safety protection, on-site control and environmental protection, and proposed the establishment of safety supervision and early warning system based on relevant discipline theories and methods. .
Most of the research on safety performance focuses on the field of construction engineering and mining engineering. For the research of distributed new energy generation under smart grid, research on safety cost control and safety performance is still rare, especially for the research on safety performance of wind farms. No reports have been reported. This paper starts with the security cost control strategy, based on the game model analysis of stakeholders, discusses the characteristics of wind farm project safety performance, and proposes corresponding countermeasures.

\section{ESTABLISHING THE MODEL}

\section{A. Basic Assumptions}

There are some assumptions for our evolutionary game model.

- $\quad$ The participants of the game model are the government power regulatory departments, wind power enterprises and power grid enterprises.

- $\quad$ For wind power enterprises, sufficient safety investment requires more safety costs. At this time, there will be no serious safety accidents; insufficient safety investment will make the safety protection of wind power insufficient, and the uncertainty of safety accidents will increase, and the accident losses will increase.

- $\quad$ As long as the power regulatory agency chooses to supervise, it will be able to find out whether the wind power enterprise's safety investment is sufficient and whether the grid receives green wind power. When the probability of a safety accident in a wind farm increases, the electricity regulatory department will have an expected loss.

- When the safety input of wind power enterprises is insufficient, the probability of unsafe operation of grid interconnection will increase, and the grid enterprises will receive the expected safety loss when receiving green wind power.

\section{B. Model Parameter Symbols}

When electric supervision department (ESD) chooses to supervise, $\mathrm{S}$ refers to the regulatory strategy and $x$ is the probability; $\mathrm{P}_{1}$ represents utility and $\mathrm{C}_{1}$ is the supervision costs. $\underline{\mathrm{S}}$ refers to the non-regulatory strategy. $\mathrm{P}_{2}$ is safety utility 
without supervision, while $C_{2}$ is expected safety loss due to increased probability of accident when not regulated.

If wind power enterprise (WPE) selects a sufficient safety investment strategy, which is represented by $\mathrm{W}$, the probability is $y$, safety gain is $\mathrm{P}_{3}$ and $\mathrm{C}_{3}$ is sufficient safety investment. If being supervised, it gets reward $R_{1}$. When safety investment is insufficient $\left(\mathrm{C}_{4}\right), \underline{\mathrm{W}}$ indicates that the safety investment is insufficient. $\mathrm{P}_{4}$ is the revenue and $\mathrm{F}_{1}$ is punishment by the electric supervision department. When the grid receives green wind power, it can get green subsidies $\mathrm{P}_{7}$ and expected safety loss is $C_{8}$ due to insufficient safety investment; otherwise, $C_{7}$ is expected safety loss.

For power grid enterprise (PGE), $z$ is the probability of receiving green wind power connected to the grid, $G$ indicates the strategy of receiving wind power. At the same time, $\mathrm{P}_{5}$ is utility and $C_{5}$ is the cost. $R_{2}$ is the reward and $C_{9}$ is expected safety loss. If not receive, which is indicated by $\underline{\mathrm{G}}$, utility and cost are respectively $\mathrm{P}_{6}$ and $\mathrm{C}_{6}$. $\mathrm{F}_{2}$ is the punishment.

The benefits of the parties in the various combinations of strategies are listed in Table I.

TABLE I. INCOME TABLE OF THE THREE PARTIES OF THE GAME

\begin{tabular}{|l|l|l|l|l|}
\hline $\begin{array}{l}\text { Strategy } \\
\text { group }\end{array}$ & $\begin{array}{l}\text { Probability } \\
\text { of Strategy } \\
\text { group }\end{array}$ & $\begin{array}{l}\text { Electric } \\
\text { supervision } \\
\text { department }\end{array}$ & $\begin{array}{l}\text { Wind power } \\
\text { enterprise }\end{array}$ & $\begin{array}{l}\text { Power grid } \\
\text { enterprise }\end{array}$ \\
\hline$(\mathrm{S}, \mathrm{W}, \mathrm{G})$ & $(x, y, z)$ & $\mathrm{P}_{1}-\mathrm{C}_{1}-\mathrm{R}_{1}-\mathrm{R}_{2}$ & $\mathrm{P}_{3}-\mathrm{C}_{3}+\mathrm{R}_{1}+\mathrm{P}_{7}$ & $\mathrm{P}_{5}-\mathrm{C}_{5}+\mathrm{R}_{2}$ \\
\hline$(\mathrm{S}, \underline{\mathrm{W}}, \mathrm{G})$ & $(x, 1-y, z)$ & $\mathrm{P}_{1}-\mathrm{C}_{1}+\mathrm{F}_{1}-\mathrm{R}_{2}$ & $\mathrm{P}_{4}-\mathrm{C}_{4}-\mathrm{F}_{1}-\mathrm{C}_{8}$ & $\mathrm{P}_{5}-\mathrm{C}_{5}-\mathrm{C}_{9}+\mathrm{R}_{2}$ \\
\hline$(\mathrm{S}, \mathrm{W}, \underline{\mathrm{G}})$ & $(x, y, 1-z)$ & $\mathrm{P}_{1}-\mathrm{C}_{1}-\mathrm{R}_{1}+\mathrm{F}_{2}$ & $\mathrm{P}_{3}-\mathrm{C}_{3}+\mathrm{R}_{1}$ & $\mathrm{P}_{6}-\mathrm{C}_{6}-\mathrm{F}_{2}$ \\
\hline$(\mathrm{S}, \underline{\mathrm{W}}, \underline{\mathrm{G}})$ & $(x, 1-y, 1-z)$ & $\mathrm{P}_{1}-\mathrm{C}_{1}-\mathrm{F}_{1}+\mathrm{F}_{2}$ & $\mathrm{P}_{4}-\mathrm{C}_{4}-\mathrm{F}_{1}-\mathrm{C}_{7}$ & $\mathrm{P}_{6}-\mathrm{C}_{6}-\mathrm{F}_{2}$ \\
\hline$(\underline{\mathrm{S}}, \mathrm{W}, \mathrm{G})$ & $(1-x, y, z)$ & $\mathrm{P}_{2}$ & $\mathrm{P}_{3}-\mathrm{C}_{3}+\mathrm{P}_{7}$ & $\mathrm{P}_{5}-\mathrm{C}_{5}$ \\
\hline$(\underline{\mathrm{S}}, \underline{\mathrm{W}}, \mathrm{G})$ & $(1-x, 1-y, z)$ & $\mathrm{P}_{2}-\mathrm{C}_{2}$ & $\mathrm{P}_{4}-\mathrm{C}_{4}-\mathrm{C}_{8}$ & $\mathrm{P}_{5}-\mathrm{C}_{5}-\mathrm{C}_{9}$ \\
\hline$(\underline{\mathrm{S}}, \mathrm{W}, \underline{\mathrm{G}})$ & $(1-x, y, 1-z)$ & $\mathrm{P}_{2}$ & $\mathrm{P}_{3}-\mathrm{C}_{3}$ & $\mathrm{P}_{6}-\mathrm{C}_{6}$ \\
\hline$(\underline{\mathrm{S}}, \underline{\mathrm{W}}, \underline{\mathrm{G}})$ & $(1-x, 1-y, 1-z)$ & $\mathrm{P}_{2}-\mathrm{C}_{2}$ & $\mathrm{P}_{4}-\mathrm{C}_{4}-\mathrm{C}_{7}$ & $\mathrm{P}_{6}-\mathrm{C}_{6}$ \\
\hline
\end{tabular}

III. AnAlyzing The Evolutionary GAme Model

To study the Nash equilibrium state of the game model, it is necessary to use the replicon dynamic to simulate the learning and evolution mechanism of the player, mainly to analyze the influence of the condition parameters and the decision probability of the parties on the evolution.

\section{A. Analysis of Evolutionary Stability Strategy of Electric Supervision Department}

The expected benefit of the ESD's choice of supervision is $U_{S}$, the expected return of un-regulated is $U_{S}$, and the average expected return is $U_{S \underline{s}}$, the replicon dynamics ${ }^{[3]}$ is:

$$
\mathrm{S}(x)=\mathrm{d} x / \mathrm{d} t=x\left(\mathrm{U}_{\mathrm{S}}-\mathrm{U}_{\mathrm{SS}}\right)=x(1-x) \mathrm{s}(y, z)
$$

$$
=x(1-x)\left[\left(\mathrm{P}_{1}+\mathrm{F}_{1}-\mathrm{C}_{1}+\mathrm{F}_{2}-\mathrm{P}_{2}+\mathrm{C}_{2}\right)-\left(\mathrm{F}_{1}+\mathrm{R}_{1}+\mathrm{C}_{2}\right) y-\left(\mathrm{F}_{2}+\mathrm{R}_{2}\right) z\right](1)
$$

When $\mathrm{S}(x)=0$, there are 2 stable points: $x=0, x=1$.

Let $\mathrm{s}\left(\delta_{y}, z\right)=0$ or $\mathrm{s}\left(y, \delta_{z}\right)=0$. When $y=\delta_{y}$ or $z=\delta_{z}$, $\mathrm{S}(x) \equiv 0$, then $x$ is stable throughout the interval.

Since the evolutionary stability strategy needs to satisfy

$\partial \mathrm{S}(x) / \partial x<0$, then

$$
\partial \mathrm{S}(x) / \partial x=(1-2 x) \mathrm{s}(y, z)
$$

Because of $0<y<1,0<\mathrm{z}<1$, s $(y, z)<\mathrm{P}_{1}+\mathrm{F}_{1}-\mathrm{C}_{1}+\mathrm{F}_{2}-\mathrm{P}_{2}+\mathrm{C}_{2}$.

1) When $\mathrm{p}_{1}+\mathrm{f}_{1}-\mathrm{c}_{1}+\mathrm{f}_{2}-\mathrm{p}_{2}+\mathrm{c}_{2}<0, \quad \mathrm{~s}(y, \mathrm{z})<0, \quad \partial \mathrm{s}(x) /\left.\partial x\right|_{x=0}<0$, $x=0$ is the evolutionary stability strategy

It can be seen that in this case, the regulatory benefits are the social benefits and penalties obtained after the removal of the supervision costs, which is less than the gains from the non-regulatory, and the ESD will not choose to supervise.

At this time, the strategic choice of WPE and PGE does not affect the ESD.

2) When $\mathrm{P}_{1}+\mathrm{F}_{1}-\mathrm{C}_{1}+\mathrm{F}_{2}-\mathrm{P}_{2}+\mathrm{C}_{2}>0$, analyze the influence of $y$ and $z$ on $x$.

a) $y>\delta_{y}$, then $\partial \mathrm{S}(x) /\left.\partial x\right|_{x=0}<0, \quad x=0$ is an evolutionary stability strategy; $y<\delta_{y}$, then $\partial \mathrm{S}(x) /\left.\partial x\right|_{x=1}<0, \quad x=0$ is an evolutionary stability strategy.

That is, an increase in $y$ causes the strategy of $x$ to go from 1 to 0 . With the increasing probability of WPE investing sufficient safety costs, the ESD will be more assured that the probability of selecting supervision will be reduced.

b) Similarly, $z>\delta_{z}, \quad x=0$ is an evolutionary stability strategy; $z<\delta_{z}, x=1$ is an evolutionary stability strategy.

The increase in $z$ also causes the strategy of $x$ to go from 1 to 0 . In the same way, the greater the possibility that PGE choose to receive green wind power and connect to the grid, the ESD is more likely to choose not to supervise.

3) Influence of Conditional Parameters on Evolutionary Equilibrium.

In the $x y z$ coordinate system, the conditional constraint $0<x<1,0<y<1,0<z<1$ constitutes the game's three-party strategy space, and $\mathrm{s}(y, z)=0$ is the plane $\alpha$, as shown in Figure $\mathrm{I}(\mathrm{a})$, and the intercept is $\lambda_{1}, \lambda_{2}$. When the $\left[\begin{array}{ll}x y & z\end{array}\right]$ strategy combination is above the plane $\alpha, \partial S(x) /\left.\partial x\right|_{x=0}<0$, the ESD's evolutionary stability strategy chooses not to supervise $x=0$. When the $\left[\begin{array}{lll}x & y & z\end{array}\right]$ strategy combination is below the plane $\alpha$, the ESD's evolutionary stability strategy selects supervision for $x=1$.

Let

$$
\lambda_{1}=\left(\mathrm{P}_{1}+\mathrm{F}_{1}-\mathrm{C}_{1}+\mathrm{F}_{2}-\mathrm{P}_{2}+\mathrm{C}_{2}\right) /\left(\mathrm{F}_{1}+\mathrm{R}_{1}+\mathrm{C}_{2}\right)
$$

$$
\lambda_{2}=\left(\mathrm{P}_{1}+\mathrm{F}_{1}-\mathrm{C}_{1}+\mathrm{F}_{2}-\mathrm{P}_{2}+\mathrm{C}_{2}\right) /\left(\mathrm{F}_{2}+\mathrm{R}_{2}\right)
$$


When $\mathrm{C}_{1}$ increases, $\lambda_{1}$ and $\lambda_{2}$ decreases and the upper space increases. That is, as the cost of safety supervision increases, the electric supervision department will have a greater probability of not supervising.

When $\lambda_{1}<1, \lambda_{2}<1$, the volume of the lower space:

$$
\mathrm{V}_{\text {low }}=\left(\mathrm{P}_{1}+\mathrm{F}_{1}-\mathrm{C}_{1}+\mathrm{F}_{2}-\mathrm{P}_{2}+\mathrm{C}_{2}\right)^{2} /\left[2\left(\mathrm{~F}_{1}+\mathrm{R}_{1}+\mathrm{C}_{2}\right)\left(\mathrm{F}_{2}+\mathrm{R}_{2}\right)\right]
$$

Thus $\partial \mathrm{V}_{\text {low }} / \partial \mathrm{C}_{2}>0$. As $\mathrm{C}_{2}$ increases, the lower space will increase. That is, when the risk of safety accidents caused by non-regulation increases and the expected safety loss increases, the electric supervision department will tend to choose a supervision strategy.

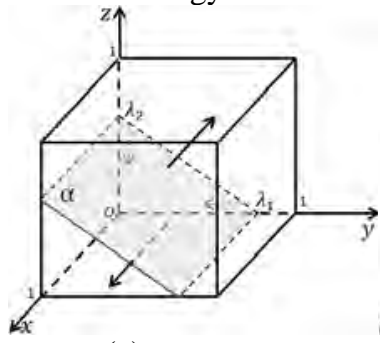

(a)

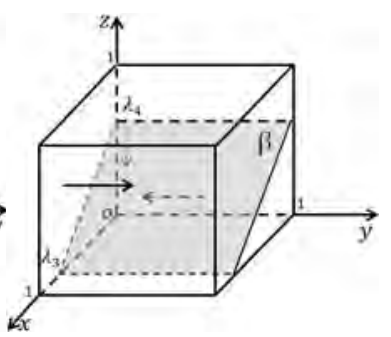

(b)
FIGURE I. THE EFFECT OF OTHER CONDITIONAL CHANGES ON $x$ (a) AND $y(b)$

At present, China's power regulation system is still not perfect, and the supervision cost is high. Therefore, on the one hand, the state should strengthen the construction of ecological civilization and promote the development of green energy, thereby improving the social benefits of supervision by the electric supervision department. On the other hand, it should speed up the reform of the electric power supervision system, improve the regulatory structure and supervision procedures, and optimize the cost of electricity supervision. It is necessary to balance the relationship with wind power enterprises and power grid enterprises to form a good game situation.

\section{B. Analysis of Evolutionary Stability Strategy of Wind Power Enterprise}

The expected return of WPE to choose sufficient safety investment is $U_{W}$, the expectation of insufficient safety investment is $U_{\underline{W}}$, the average expected return is $U_{W \underline{w}}$, the replicon dynamics is:

$$
\begin{gathered}
\mathrm{W}(y)=\mathrm{d} y / \mathrm{d} t=y\left(\mathrm{U}_{\mathrm{W}}-\mathrm{U}_{\mathrm{w} \underline{\mathrm{w}}}\right)=y(1-y) \mathrm{w}(x, \mathrm{z}) \\
=y(1-y)\left[\left(\mathrm{P}_{3}-\mathrm{C}_{3}-\mathrm{P}_{4}+\mathrm{C}_{4}+\mathrm{C}_{7}\right)+\left(\mathrm{F}_{1}+\mathrm{R}_{1}\right) x+\left(\mathrm{P}_{7}+\mathrm{C}_{8}-\mathrm{C}_{7}\right) \mathrm{z}\right]
\end{gathered}
$$

When $\mathrm{W}(y)=0$, there are 2 stable points: $y=0, y=1$.

Let $\mathrm{w}\left(\eta_{x}, z\right)=0$ or $\mathrm{w}\left(x, \eta_{z}\right)=0$. When $x=\eta_{x}$ or $z=\eta_{z}, \mathrm{~W}(y) \equiv 0$, then $\mathrm{y}$ is stable throughout the interval.

Since the evolutionary stability strategy needs to satisfy

$\partial \mathrm{W}(y) / \partial y<0$, then

$$
\partial \mathrm{W}(y) / \partial y=(1-2 y) \mathrm{w}(x, z)
$$

Because of

$0<x<1,0<\mathrm{Z}<1, \mathrm{w}(x, \mathrm{Z})<\mathrm{P}_{3}-\mathrm{C}_{3}-\mathrm{P}_{4}+\mathrm{C}_{4}+\mathrm{C}_{7}+\mathrm{F}_{1}+\mathrm{R}_{1}+\mathrm{P}_{7}+\mathrm{C}_{8}-\mathrm{C}_{7}$.

1) When $\mathrm{P}_{3}-\mathrm{C}_{3}-\mathrm{P}_{4}+\mathrm{C}_{4}+\mathrm{C}_{7}+\mathrm{F}_{1}+\mathrm{R}_{1}+\mathrm{P}_{7}+\mathrm{C}_{8}-\mathrm{C}_{7}<0$, w $(x, \mathrm{z})<0$, $\partial \mathrm{W}(y) /\left.\partial y\right|_{y=0}<0, y=0$ is the evolutionary stability strategy.

If WPE chooses to invest sufficient safety cost less than insufficient revenue, regardless of ESD and PGE regulatory testing, WPE's ultimate stability strategy is insufficient security investment.

2) When $\mathrm{P}_{3}-\mathrm{C}_{3}+\mathrm{R}_{1}+\mathrm{P}_{7}>\mathrm{P}_{4}-\mathrm{C}_{4}-\mathrm{F}_{1}-\mathrm{C}_{8}$, analyzing the influence of $x$ and $z$ on $y$.

a) $x>\eta_{x}$, then $\partial \mathrm{W}(y) /\left.\partial y\right|_{y=1}<0, y=1$ is an evolutionary stability strategy; $x<\eta_{x}$, then $\partial \mathrm{W}(y) /\left.\partial y\right|_{y=0}<0, \quad y=0$ is an evolutionary stability strategy.

That is, the increase of $x$ will make the strategy of $y$ from 0 to 1 . As the probability of elective supervision by the ESD increases, WPE will more likely to invest sufficient safety costs.

b) Similarly, $z>\eta_{z}, \quad y=1$ is an evolutionary stability strategy; $z<\eta_{z}, y=0$ is an evolutionary stability strategy.

That is, the increase of $z$ will also make the strategy of $y$ from 0 to 1 . The greater the probability that PGE choose to accept green wind power, the greater the probability that WPE will have more adequate safety investment.

c) Influence of Conditional Parameters on Evolutionary Equilibrium.

In the $x y z$ coordinate system, $\mathrm{w}(x, z)=0$ is a plane $\beta$, as shown in Figure I(b), the intercept is $\lambda_{3}, \lambda_{4}$. When the $\left[\begin{array}{lll}x & y & z\end{array}\right]$ strategy combination is above the plane $\beta, \partial \mathrm{W}(y) /\left.\partial y\right|_{y=1}<0$, the WPE's evolutionary stability strategy is $y=1$; When the $\left[\begin{array}{lll}x & y z & z\end{array}\right]$ strategy combination is below the plane $\beta$, the WPE's evolutionary stability strategy is $y=0$.

Let

$$
\begin{aligned}
& \lambda_{3}=\left(-\mathrm{P}_{3}+\mathrm{C}_{3}+\mathrm{P}_{4}-\mathrm{C}_{4}-\mathrm{C}_{7}\right) /\left(\mathrm{F}_{1}+\mathrm{R}_{1}\right) \\
& \lambda_{4}=\left(-\mathrm{P}_{3}+\mathrm{C}_{3}+\mathrm{P}_{4}-\mathrm{C}_{4}-\mathrm{C}_{7}\right) /\left(\mathrm{P}_{7}+\mathrm{C}_{8}-\mathrm{C}_{7}\right)
\end{aligned}
$$

When $\mathrm{R}_{1}$ or $\mathrm{F}_{1}$ increases, $\lambda_{3}$ decreases; when $\mathrm{P}_{7}$ or $\mathrm{C}_{8}$ increases, $\lambda_{4}$ decreases, and the upper space increases. As the incentives or penalties for WPE increase, or PGE receives subsidies for green wind power and the expected safety losses increase, WPE will have a higher probability of choosing to invest sufficient safety costs. When $C_{3}$ increases or $C_{4}$ decreases, $\lambda_{3}$ and $\lambda_{4}$ will increase, the increase in adequate safety costs that WPE should invest in will reduce the benefits of adequate safety investment strategies, and WPE will be more inclined to choose not to invest adequately. 


\section{Analysis of Evolutionary Stability Strategy of Power Grid Enterprise}

The expected benefit of grid companies choosing to receive wind power and detecting grid connection security is $U_{G}$, the expected utility of not receiving wind power is $U_{G}$, the average expected return is $\mathrm{U}_{\mathrm{GG}}$, the replicon dynamics is:

$$
\begin{aligned}
& \mathrm{G}(\mathrm{z})=\mathrm{d} z / \mathrm{d} t=\mathrm{z}\left(\mathrm{U}_{\mathrm{G}}-\mathrm{U}_{\mathrm{GG}}\right)=\mathrm{z}(1-\mathrm{z}) \mathrm{g}(x, y) \\
& =\mathrm{z}(1-\mathrm{z})\left[\left(\mathrm{P}_{5}-\mathrm{C}_{5}-\mathrm{C}_{9}-\mathrm{P}_{6}+\mathrm{C}_{6}\right)+\left(\mathrm{F}_{2}+\mathrm{R}_{2}\right) x+\mathrm{C}_{9} y\right]
\end{aligned}
$$

When $G(z)=0$, there are 2 stable points: $z=0, z=1$.

Let $g\left(\varphi_{x}, y\right)=0$ or $g\left(x, \varphi_{y}\right)=0$. When $x=\varphi_{x}$ or $y=\varphi_{y}, \mathrm{G}(z) \equiv 0$, then $\mathrm{y}$ is stable throughout the interval.

Since the evolutionary stability strategy needs to satisfy

$\partial \mathrm{G}(\mathrm{z}) / \partial \mathrm{z}<0$, then

$$
\partial \mathrm{G}(\mathrm{z}) / \partial \mathrm{z}=(1-2 \mathrm{z}) \mathrm{g}(x, y)
$$

Because of $0<x<1,0<y<1, \mathrm{~g}(x, y)<\mathrm{P}_{5}-\mathrm{C}_{5}-\mathrm{P}_{6}+\mathrm{C}_{6}+\mathrm{F}_{2}+\mathrm{R}_{2}$.

1) When $\mathrm{P}_{5}-\mathrm{C}_{5}-\mathrm{P}_{6}+\mathrm{C}_{6}+\mathrm{F}_{2}+\mathrm{R}_{2}<0, \mathrm{~g}(x, y)<0, \partial \mathrm{G}(\mathrm{z}) /\left.\partial \mathrm{z}\right|_{z=0}<0$, $\mathrm{z}=0$ is the evolutionary stability strategy.

If the minimum revenue for PGE not receiving green wind power is greater than the maximum revenue received, PGE will choose not to receive green wind power strategies regardless of power regulation.

2) When $\mathrm{P}_{5}-\mathrm{C}_{5}-\mathrm{P}_{6}+\mathrm{C}_{6}+\mathrm{F}_{2}+\mathrm{R}_{2}>0$, analyzing the influence of $y$ on $z$.

$y>\varphi_{y}$, then $\partial \mathrm{G}(z) /\left.\partial z\right|_{z=1}<0, z=1$ is an evolutionary stability strategy; $y<\varphi_{y}$, then $\partial \mathrm{G}(z) /\left.\partial z\right|_{z=0}<0, z=0$ is an evolutionary stability strategy.

When $y$ is reduced, the evolution strategy of $z$ tends from 1 to 0 . It shows that when WPE has a greater probability of choosing an insufficient safety investment strategy, PGE will adopt a strategy of not accepting green wind power to ensure the loss reduction.

3) Influence of Conditional Parameters on Evolutionary Equilibrium.

In the $x y z$ coordinate system, $g(x, y)=0$ is a plane $\gamma$, as shown in Figure II, and the intercept of the $x$ and $y$ coordinate axes is $\lambda_{5}$ and $\lambda_{6}$.

Let

$$
\begin{aligned}
& \lambda_{5}=\left(-\mathrm{P}_{5}+\mathrm{C}_{5}+\mathrm{C}_{9}+\mathrm{P}_{6}-\mathrm{C}_{6}\right) /\left(\mathrm{F}_{2}+\mathrm{R}_{2}\right) \\
& \lambda_{6}=\left(-\mathrm{P}_{5}+\mathrm{C}_{5}+\mathrm{C}_{9}+\mathrm{P}_{6}-\mathrm{C}_{6}\right) / \mathrm{C}_{9}
\end{aligned}
$$

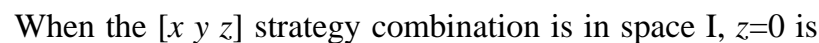
an evolutionary stability strategy, and when $[x y z]$ is in space II, $z=1$ is an evolutionary stabilization strategy. When $C_{5}$ decreases or $C_{6}$ increases, $\lambda_{5}$ and $\lambda_{6}$ decrease and the space $I$ is reduced. Therefore, when the safety cost of accepting green wind power is reduced or the policy cost of not receiving is increased, the decrease in the income of not receiving green wind power will make PGE more inclined to choose to receive green wind power.

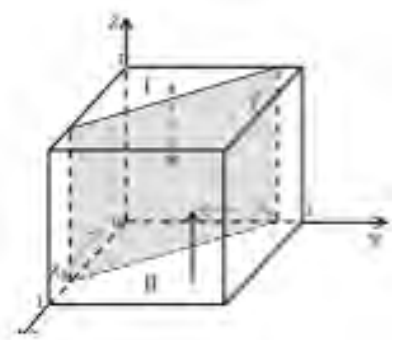

FIGURE II. THE EFFECT OF OTHER CONDITIONAL CHANGES ON z

Because the volume of space I is

$$
\mathrm{V}_{\mathrm{I}}=\left(-\mathrm{P}_{5}+\mathrm{C}_{5}+\mathrm{C}_{9}+\mathrm{P}_{6}-\mathrm{C}_{6}\right)^{2} /\left[2 \mathrm{C}_{9}\left(\mathrm{~F}_{2}+\mathrm{R}_{2}\right)\right]
$$

Thus $\partial \mathrm{V}_{\mathrm{I}} / \partial \mathrm{C}_{9}>0$. When $\mathrm{C}_{9}$ increases, the $\mathrm{V}_{\mathrm{I}}$ also increases. That is, as the expected loss of accepting green wind power increases, PGE will choose not to accept as a stable strategy, correctly control the expected loss, and can guide PGE to choose to receive the green wind power strategy.

\section{CONCLUSION}

Through the above research, the following conclusions are drawn:

Firstly, this study comprehensively analyzes the three-party evolutionary game of government, wind power enterprises, and power grid enterprises, and considered that their strategic options are based on the best performance of the safety inputs.

In addition, the government's reward and punishment measures and adequate safety investment of wind power enterprises will become the bridge for the grid enterprises to receive green wind power from the short-term passive to longterm initiative to receive green wind power, which also lays a foundation for users to provide safe and reliable clean energy.

Finally, in order to improve the safety performance of green wind power, it is essential to play the role played by the government and power users in the safety investment of enterprises.

\section{ACKNOWLEDGMENT}

The authors thank the financial support of the Shanghai Social Science Fund Project under grant No. 2016BGL001 and the National Social Science Fund Project under grant No. 17BGL010. 


\section{REFERENCES}

[1] Jimmie Hinze, Matthew Hallowell, Kevin Baud. "Construction-Safety Best Practices and Relationships to Safety Performance,” Journal of Construction Engineering and Management, vol.139,Oct 2013.

[2] Yan J, Ji Y, Weiyan M. "Research on Early Warning Model Establish for Electrical Safety Supervision System in China," 2009 Second International Conference on Future Information Technology and Management Engineering. 2009.

[3] Wu, Hao, Mei-ying YANG, and Liang-you CHEN. "An Analyzes on complexity and evolutionary stability in co-petition games," Systems Engineering-theory \& Practice, No.2, 2004, pp. 90-94.

[4] Yingbin Feng. "Effect of safety investments on safety performance of building projects,” Safety Science, vol. 59, 2013, pp. 28-45.

[5] Tremblay A, Badri A. "Assessment of occupational health and safety performance evaluation tools: state of the art and challenges for small and medium-sized enterprises. " Safety science, vol. 101, 2018, pp. 260267.

[6] Stephanie L. Morrow, G. Kenneth Koves, Valerie E. Barnes "Exploring the relationship between safety culture and safety performance in U.S. nuclear power operations,” Safety science, vol. 69, 2014, pp. 37-47. 